\title{
Evaluation of Vicine as a Corrosion Inhibitor for Carbon Steel Alloy
}

\author{
Hadi Z. Al-Sawaad, Naem T. Faili and Ali. H. Essa \\ University of Basrah, College of Science, Department of Chemistry, Basrah, Iraq
}

Received July 30, 2017; accepted February 01, 2018

\begin{abstract}
In the present study, vicine was extracted from sunflower seeds, and has been evaluated as a corrosion inhibitor for carbon steel alloy, at different concentrations and temperatures. Vicine showed maximum inhibiting efficiency of $97 \%$, at $25{ }^{\circ} \mathrm{C}$. The inhibitor's efficiency was reduced when the temperature increased. Kinetic parameters $\left(\mathrm{E}_{\mathrm{a}}, \Delta \mathrm{H}^{*}, \Delta \mathrm{G}^{*}\right.$ and $\left.\Delta \mathrm{S}^{*}\right)$ were calculated. The corrosion reaction was suppressed by vicine, because the energy barrier of the corrosion reaction was increased, and it became non-spontaneous, by an endothermic process. Furthermore, $\Delta \mathrm{H}_{\mathrm{ads}}, \Delta \mathrm{G}_{\mathrm{ads}}$ and $\Delta \mathrm{S}$ ads were also calculated, and showed that the inhibitor was physically adsorbed by a spontaneous and exothermic process. The corrosion was inhibited by simple blocking the reaction sites. The adsorption process obeyed the Langmuir adsorption isotherm. The theoretical and experimental studies depicted that the inhibitor worked by a mixture of physicalchemical adsorption modes.
\end{abstract}

Keywords: corrosion inhibitors, vicine, acidic corrosive media, hydrochloric acid, carbon steel alloy.

\section{Introduction}

Carbon steel is an important type of iron alloy that is more used in engineering materials, to produce $85 \%$ of the annual steel production worldwide. Iron alloys are used in different areas, e.g., in marine applications, chemical processing, petroleum production and refining [1-3]. The corrosion of iron alloys significantly limits several applications. In fact, corrosion occurs either by the two different metals or alloys, and also if that metal or alloy is present in corrosive environments, such as saline, basic or acidic media. The jeopardizing of metals or alloys structures creates economics and safety issues, and causes pollution [4-6]. Acids such as hydrochloric acid are frequently used as pickling for cleaning processes in industry. Unfortunately, acid media are corrosive [7-9]. Hence, organic corrosion inhibitors are one of the treatments used to reduce the

\footnotetext{
* Corresponding author. E-mail address: hadiziara@yahoo.com
} 
corrosive effect of metals or alloys, due to their ability to adsorb onto the metal surface, either by physisorption or chemisorption [10].

A common corrosion inhibiting mechanism involves the formation of a coating, often a passivation layer, which prevents metal corrosion.

The corrosive agents are generally oxygen, hydrogen sulfide, and carbon dioxide. Oxygen is generally removed by reductive inhibitors, such as amines and hydrazides.

Corrosion inhibitors are chemically adsorbed onto the metals surface, because they contain either one or more types of hetero atoms, such as N, S, P and O.

Inhibitors usually show significant inhibition efficiency, although most of these substances are not only expensive, but also toxic. Therefore, plants have been used as a natural source of corrosion inhibitors, because of their low cost, abundant availability and, more important, their environmental safety [11-13].

In the present study, vicine was extracted from sunflower seeds; then, we studied its effect as a natural source of corrosion inhibitor for carbon steel alloy against acidic media, at different temperatures.

\section{Experimental}

\section{Vicine extraction [14]}

$300 \mathrm{~mL}$ from $2 \%$ acetic acid were added to $20 \mathrm{~g}$ of sunflower seeds dried powder. Then, the mixture was heated in a water bath to $70{ }^{\circ} \mathrm{C}$, for 8 hours, filtered and washed by an alcoholic brine solution of butanol. The organic layer was separated, evaporated under reduced pressure, and then removed, while the acidic aqueous layer was dried by putting it in a pottery dish for 24 hours, to obtain vicine. Then, vicine was kept in a dark container in a refrigerator, until it was used. Vicine's structure is shown in Fig. 1.<smiles></smiles>

Figure 1. Vicine's structure (2,6-diamino-5-( $\beta$-D-glucopyranosyloxy)-4(1H)pyrimidinone).

\section{Corrosion study}

Alloy composition

The composition of the carbon steel alloy used in this study is illustrated in Table 1.

Table 1. Carbon steel alloy chemical composition.

\begin{tabular}{cc}
\hline Alloy & Composition \\
\hline Carbon steel & $0.3 \% \mathrm{C}, 1.2 \% \mathrm{Mn}, 0.05 \% \mathrm{P}, 0.06 \% \mathrm{~S}, \mathrm{Fe}$ for balance (\%by weight) \\
\hline
\end{tabular}




\section{Specimens' preparation}

A carbon steel disc (1.4-1.7 cm diameter and 2-3 mm thickness) was grind and polished on its opposing faces, by an emery cloth paper, to 400 micron. Thereafter, the specimens were washed with distilled water and ethanol, and then dried with hot air. The specimens were stored in a desiccator containing silica gel, during the interval between polishing and polarization measurements.

\section{Results and discussion}

In this study, Tafel plots were used to evaluate vicine as a corrosion inhibitor in $0.1 \mathrm{M}$ hydrochloric acid. The inhibitor concentration and the temperature effects were evaluated at $25^{\circ} \mathrm{C}, 35^{\circ} \mathrm{C}, 45^{\circ} \mathrm{C}$ and $55^{\circ} \mathrm{C}$, as well.

\section{Vicine concentration effect at a constant temperature}

Fig. 2 shows Tafel plots for the carbon steel alloy, at 10, 20, 30, 40, and 50 ppm of vicine, compared to the blank (corrosive environment), at 25, 35, 45, and 55 ${ }^{\circ} \mathrm{C}$, respectively.
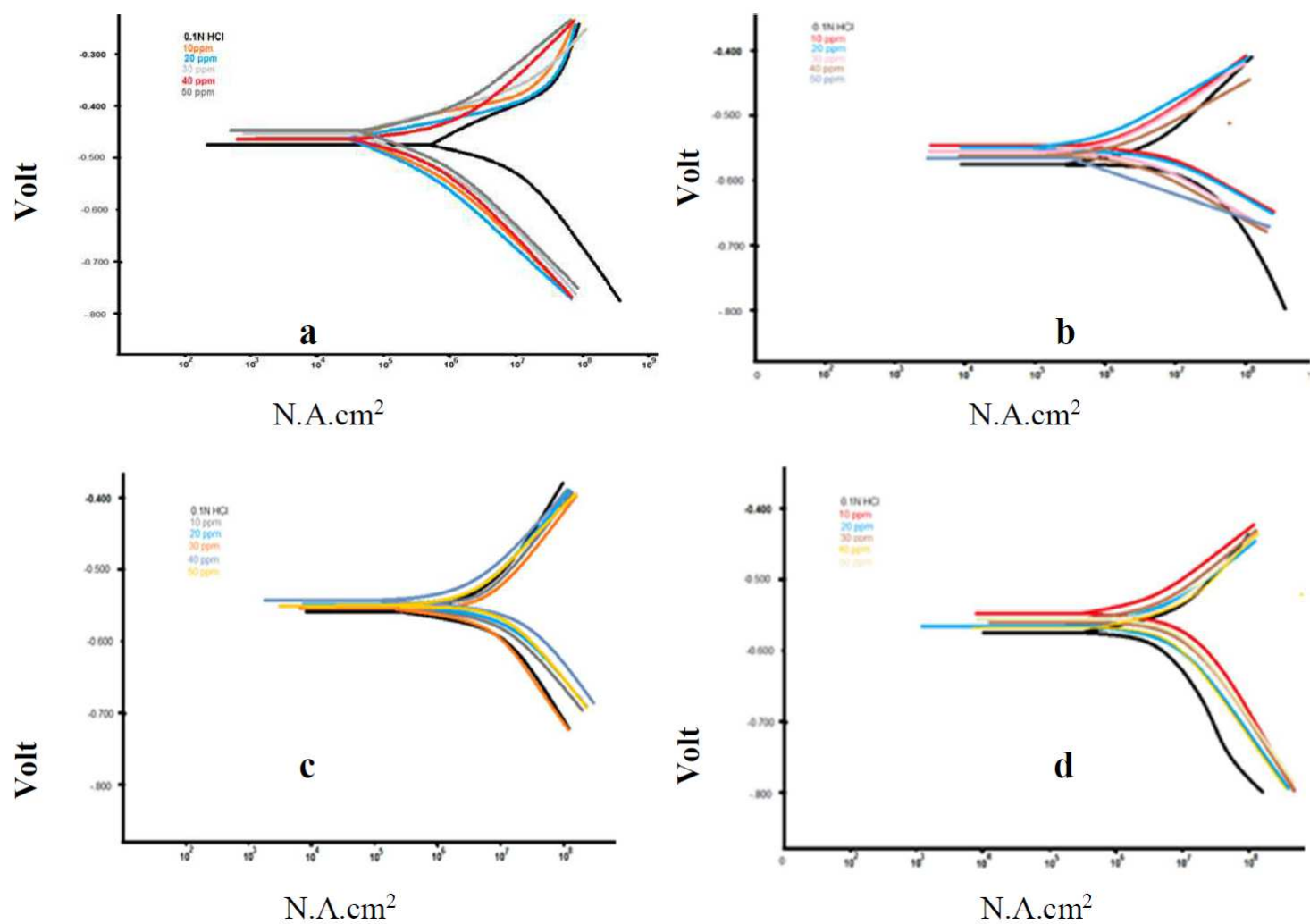

Figure 2. Tafel plots for carbon steel alloy at 10, 20, 30, 40, and $50 \mathrm{ppm}$ of vicine, in $0.1 \mathrm{M} \mathrm{HCl}$ at a: $25^{\circ} \mathrm{C}, \mathbf{b}: 35^{\circ} \mathrm{C}$, c: $45^{\circ} \mathrm{C}$ and $\mathbf{d}: 55^{\circ} \mathrm{C}$.

The electrochemical data obtained from Fig. 2 are summarized in Table 2.

We have summarized the data from Fig. 2 in Table 2. Table 2 showed that the increase in the inhibitor concentration at $25^{\circ} \mathrm{C}$ led to a decrease in the corrosion current density and corrosion rate, while the resistance polarization and inhibition efficiency were increased. The same conclusions were found at 35, 45, and 55 
${ }^{\circ} \mathrm{C}$. However, when we made a comparison between the different temperatures effect on the inhibition efficiency, we concluded that the inhibition efficiencies at $25^{\circ} \mathrm{C}$ were higher than at $35^{\circ} \mathrm{C}$, at which they were higher than at $45^{\circ} \mathrm{C}$ and, at this temperature, they were higher than at $55^{\circ} \mathrm{C}[15,19-20]$.

Table 2. Electrochemical data from the Tafel plot method, in vicine's absence and presence, at different concentrations and temperatures.

\begin{tabular}{|c|c|c|c|c|c|c|c|c|c|}
\hline Comp. & $\begin{array}{c}\text { Conc. } \\
\text { ppm }\end{array}$ & $\begin{array}{c}\text { Temp. } \\
{ }^{\circ} \mathrm{C}\end{array}$ & $\begin{array}{c}\mathbf{I}_{\text {corr }} \\
\mu \mathrm{A} \cdot \mathbf{c m}^{-2}\end{array}$ & $\begin{array}{c}\text { CR } \\
\text { mpy }\end{array}$ & $\begin{array}{c}\operatorname{Rp} \times 10^{4} \\
\Omega\end{array}$ & $\begin{array}{c}\beta_{a} \\
\text { V.decade }^{-1}\end{array}$ & $\begin{array}{c}-\beta_{\mathrm{c}} \\
\text { V.decade }^{-1}\end{array}$ & $\begin{array}{l}\text { E }_{\text {corr }} \\
\text { Volt }\end{array}$ & $\begin{array}{c}\text { Effec. } \\
\%\end{array}$ \\
\hline $\mathrm{HCl}$ & 3650 & 25 & 739.13 & 340 & 0.026 & 0.054 & - & -0.558 & - \\
\hline \multirow[t]{5}{*}{ Vicine } & 10 & 25 & 146.13 & 67.22 & 0.016 & 0.038 & 0.108 & -0.549 & 80 \\
\hline & 20 & 25 & 98.63 & 45.37 & 0.028 & 0.054 & 0.115 & -0.550 & 86 \\
\hline & 30 & 25 & 96.89 & 44.57 & 0.023 & 0.041 & 0.089 & -0.548 & 87 \\
\hline & 40 & 25 & 72.72 & 33.45 & 0.120 & 0.59 & 0.111 & -0.537 & 90 \\
\hline & 50 & 25 & 24.63 & 11.33 & 0.170 & - & 0.110 & -0.541 & 97 \\
\hline $\mathrm{HCl}$ & 3650 & 35 & 1457.17 & 670.3 & 15.04 & - & 0.082 & -0.574 & 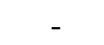 \\
\hline \multirow[t]{5}{*}{ Vicine } & 10 & 35 & 682.61 & 314.0 & 31.30 & 0.123 & 0.081 & -0.565 & 53 \\
\hline & 20 & 35 & 505.87 & 232.7 & 39.42 & - & - & -0.554 & 65 \\
\hline & 30 & 35 & 460.00 & 211.6 & 29.59 & - & 0.085 & -0.548 & 68 \\
\hline & 40 & 35 & 349.78 & 160.9 & 43.90 & - & 0.084 & -0.561 & 76 \\
\hline & 50 & 35 & 111.11 & 51.11 & 137.4 & 0.123 & 0.081 & -0.545 & 92 \\
\hline $\mathrm{HCl}$ & 3650 & 45 & 2085 & 959.1 & 38.91 & - & 0.080 & -0.554 & - \\
\hline \multirow[t]{5}{*}{ Vicine } & 10 & 45 & 1146.74 & 527.5 & 17.09 & - & 0.088 & -0.552 & 45 \\
\hline & 20 & 45 & 858.26 & 394.8 & 25.11 & - & - & -0.548 & 59 \\
\hline & 30 & 45 & 757.61 & 348.5 & 32.93 & 0.041 & - & -0.553 & 64 \\
\hline & 40 & 45 & 263.04 & 121.0 & 82.84 & 0.106 & 0.259 & -0.550 & 71 \\
\hline & 50 & 45 & 217.83 & 100.2 & 63.91 & 0.047 & 0.101 & -0.542 & 84 \\
\hline $\mathrm{HCl}$ & 3650 & 55 & 2650.22 & 1219.1 & 11.88 & - & - & -0.554 & - \\
\hline \multirow[t]{5}{*}{ Vicine } & 10 & 55 & 2015.43 & 927.1 & 11.89 & 0.125 & 0.098 & -0.567 & 24 \\
\hline & 20 & 55 & 1224.13 & 563.1 & 10.39 & 0.181 & - & -.0559 & 53 \\
\hline & 30 & 55 & 1111.96 & 511.5 & 11.00 & 0.068 & - & -0.565 & 58 \\
\hline & 40 & 55 & 1042.39 & 479.5 & 7.23 & - & - & -0.555 & 61 \\
\hline & 50 & 55 & 695.00 & 319.7 & 13.98 & - & 0.089 & -0.547 & 74 \\
\hline
\end{tabular}

The cathodic and anodic Tafel slopes (Table 2) were unremarkably altered at the inhibitor presence, i.e., the inhibitor acted blocking reaction sites for the metal surface, without changing the anodic and cathodic reaction mechanisms [16-18]. The protonated inhibitor structure and the electrochemical reactions in $\mathrm{HCl}$ presence, as a corrosive environment, are explained in equations 1 and 2.

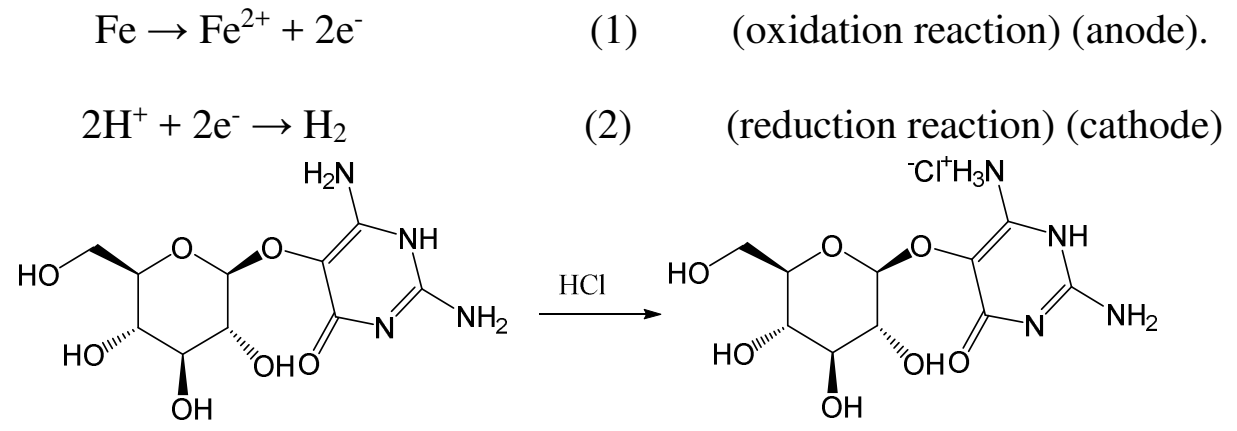

Equation 3 shows that the $\mathrm{N}$ atom protonation in vicine reduced the coordinate bond behavior with iron, through the lone pair of electrons for $\mathrm{N}$ with the $\mathrm{Fe}$ atom [18]. 


\section{Adsorption isotherm}

In order to understand the inhibition mechanism, the inhibitor adsorption behavior was studied at $25,35,45$, and $55^{\circ} \mathrm{C}$, with and without vicine. From equation 4 , the surface coverage $(\theta)$ degrees were calculated.

$$
\frac{C}{\theta}=\frac{1}{K_{a d s}}+C
$$

where $\mathrm{C}$ is the inhibitor concentration. These results depict that all the slopes were nearly close to unity.

The results showed that the Langmuir's adsorption isotherm was the best fitted isotherm, as shown in Fig. 3.

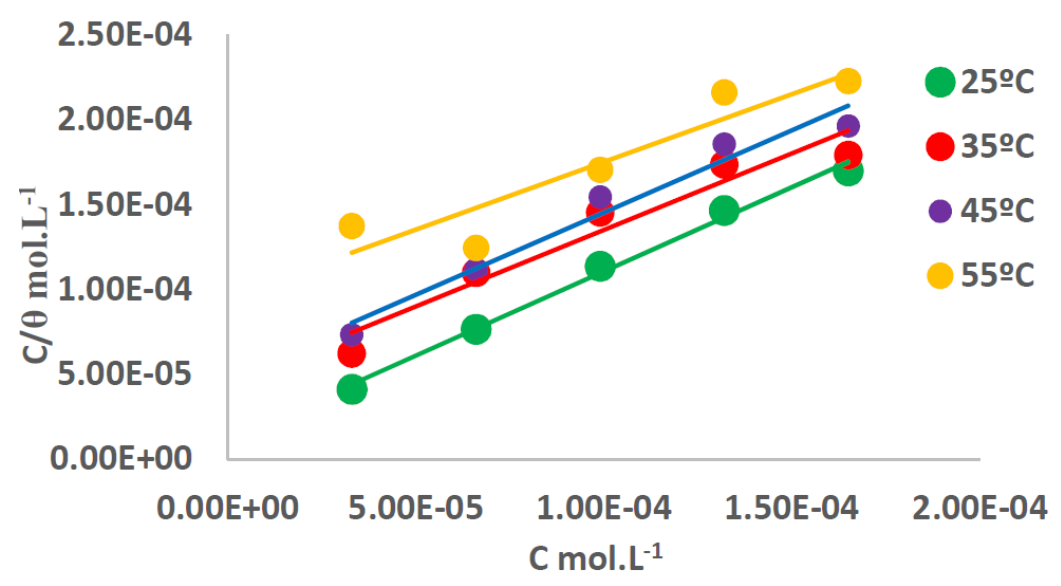

Figure 3. Adsorption isotherm for vicine, at different temperatures.

\section{Thermodynamic calculations}

The thermodynamic functions of the adsorption values $\left(\Delta \mathrm{G}_{\text {ads }}^{\circ}, \Delta \mathrm{H}_{\text {ads }}^{\circ}\right.$ and $\left.\Delta \mathrm{S}_{\text {ads }}^{\circ}\right)$ were calculated according to equations 5 and 6.

$$
\Delta G_{a d s}^{\circ}=-R T \ln 55.5 K_{a d s}
$$

where 55.5 is the water concentration in $\mathrm{mol} / \mathrm{L}, \mathrm{R}$ is the molar gas constant, and $\mathrm{T}$ is the absolute temperature [21].

The enthalpy of adsorption values was calculated using equation 6; the results are showed in Fig. 4, and the data are summarized in Table 3.

$$
\frac{\Delta G_{a d s}^{\circ}}{T}=\frac{\Delta H_{a d s}^{\circ}}{T}+k
$$






Figure 4. Thermodynamic adsorption functions for vicine on carbon steel alloy.

Table 3. Thermodynamic adsorption parameters for vicine on the carbon steel alloy surface, at different temperatures.

\begin{tabular}{ccccc}
\hline $\mathbf{K}_{\text {ads }}$ & $\begin{array}{c}\text { Temp. } \\
\mathbf{K}\end{array}$ & $\begin{array}{c}\Delta \mathbf{G}_{\text {ads }}^{\circ} \\
\mathbf{k J . m o l}^{\mathbf{1}}\end{array}$ & $\begin{array}{c}\Delta \mathbf{H}^{\circ} \text { ads, } \\
\mathbf{k J . m o l}^{-1}\end{array}$ & $\begin{array}{c}\Delta \mathbf{S}_{\text {ads }}^{\circ} \\
\mathbf{J . m o l}^{-1} \cdot \mathbf{k}^{-\mathbf{1}}\end{array}$ \\
\hline 100000 & 298 & -38.47 & -58.28 & -324.68 \\
25000 & 308 & -36.22 & -58.28 & -71.64 \\
20000 & 318 & -36.80 & -58.28 & -67.54 \\
10000 & 328 & -36.07 & -58.28 & -67.72 \\
\hline
\end{tabular}

From Table 3, vicine's adsorption process showed a spontaneous exothermic adsorption, due to the negative signs of $\Delta \mathrm{H}^{\mathbf{o}}$ ads and $\Delta \mathrm{G}^{\mathbf{o}}$ ads values. Furthermore, $\Delta \mathrm{G}_{\text {ads }}^{\mathrm{o}}$ values were higher than $-40 \mathrm{~kJ} \cdot \mathrm{mol}^{-1}$. This means that the adsorption mode was chemical adsorption [22-24]. On the other hand, the standard adsorption entropy ( $\Delta \mathrm{S}_{\text {ads }}^{\mathrm{o}}$ ) was obtained using the thermodynamic basic equation:

$$
\Delta S_{a d s}^{\circ}=\frac{\Delta H_{a d s}^{\circ}-\Delta G_{a d s}^{\circ}}{T}
$$

$\Delta S^{\mathbf{o}}$ ads negative value showed that the disordering, in the inhibitor presence, was reduced due to the inhibitor adsorption onto the metal surface [21, 25].

\section{Activation parameters calculations}

The thermodynamic functions for carbon steel dissolution, in the presence and absence of various vicine concentrations, were obtained by applying the Arrhenius equation and the transition state equation [26-28]. The data that were used to plot Arrhenius relationship are summarized in Table 4, and the plotting is shown in Fig. 5.

Other kinetic parameters $\left(\Delta \mathrm{H}^{*}, \Delta \mathrm{G}^{*}\right.$ and $\left.\Delta \mathrm{S}^{*}\right)$ can be calculated according to equations 8 and 9:

$$
\begin{array}{r}
\ln \frac{C R}{T}=\ln \frac{R}{N h}+\frac{\Delta S^{*}}{R}-\frac{\Delta H^{*}}{R T} \\
\Delta G^{*}=\Delta H^{*}-T \Delta S^{*}
\end{array}
$$


$\Delta \mathrm{H}^{*}$ was calculated by plotting $\ln (\mathrm{CR} / \mathrm{T})$ against $1 / \mathrm{T}$, as shown in Fig. 6. The slope is $\left(-\Delta H^{*} / R\right)$ and the intercept is $\left(\operatorname{lnR} / N h+\Delta S^{*} / R\right) . N$ is Avogadro's number and $h$ is the Plank's constant.

Table 4. Activation parameters for carbon steel alloy in vicine presence, at different concentrations, compared to vicine absence.

\begin{tabular}{|c|c|c|c|c|}
\hline Comp. & $\begin{array}{l}\text { Conc. } \\
\text { (ppm) }\end{array}$ & $\begin{array}{c}\text { Ea } \\
\left(\text { kJ.mol }^{-1}\right)\end{array}$ & $\begin{array}{c}\Delta \mathbf{H}^{*} \\
\left(\mathrm{~kJ} \mathrm{~mol}^{-1}\right)\end{array}$ & 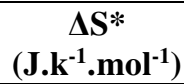 \\
\hline $\mathrm{HCl}$ & 3650 & 34.25 & 31.65 & -89.38 \\
\hline \multirow[t]{5}{*}{ Vicine } & 10 & 68.66 & 66.06 & 13.95 \\
\hline & 20 & 66.33 & 63.73 & 3.41 \\
\hline & 30 & 64.12 & 61.52 & -4.34 \\
\hline & 40 & 62.68 & 60.08 & -12.45 \\
\hline & 50 & 87.03 & 84.43 & 59.57 \\
\hline
\end{tabular}



Figure 5. Arrhenius plot for $\mathrm{HCl}$ at different vicine concentrations.

The activation parameters data are illustrated in Table 4.



Figure 6. Ln $(\mathrm{CR} / \mathrm{T})$ against $1 / \mathrm{T}$ in the presence of different vicine concentrations, compared to $\mathrm{HCl}$, at different temperatures.

From Table 4, vicine's activation energy at all concentrations is greater than in its absence. That means the alloy corrosion was reduced in vicine's presence [8, 21]. The enthalpy of the alloy dissolution reaction in $0.1 \mathrm{M} \mathrm{HCl}$, in vicine's 
presence, was higher than in the inhibitor absence. On the other hand, the positive sign of enthalpies refers to an endothermic nature of the alloy dissolution process [28-29]. Furthermore, the data in Table 4 revealed that the entropy of activation values increased in the inhibitor presence, i.e., the increasing in disordering took place from the reactant to the activated complex [21, 30]. Comparing the data in Table 4 with the inhibition efficiency in Table 3 , it is observed that IE increased when the temperature increased, which is attributed to the chemical adsorption mode [29].

\section{Theoretical studies}

Theoretical calculations were carried out using the Gaussian 03 program package [31-32]. Vicine's geometry was optimized using the density functional theory (DFT) method with B3LYP [33-35]. The calculations were performed in a 6-31G $+\mathrm{G}$ (d.p) basis set [36], whereas different calculations were carried out, such as HOMO and LUMO energies, and the dipole moment. DFT can be used to analyze the inhibition mechanism for the inhibitor on the metal or alloy surface, and describe the inhibitor-structural role against the corrosion process [37]. On the other hand, DFT method includes the version that used three parameters of Becke's functional (B3), which is called B3LYP. DFT was used to calculate the chemical potential $(\mu)$, electronegativity $(\chi)$, hardness $(\eta)$, softness $(\sigma)$, fraction of electrons transferred from the inhibitor molecule to the metallic atom $(\Delta \mathrm{N})$, and LUMO and HOMO energies [38]. HOMO and LUMO are associated with the electron donating and withdrawing of the inhibitor molecule, respectively. HOMO's high values indicate that the molecules are ready to accept electrons, in contrast with LUMO values; HOMO and LUMO levels of vicine are shown in Fig. 7.



HOMO

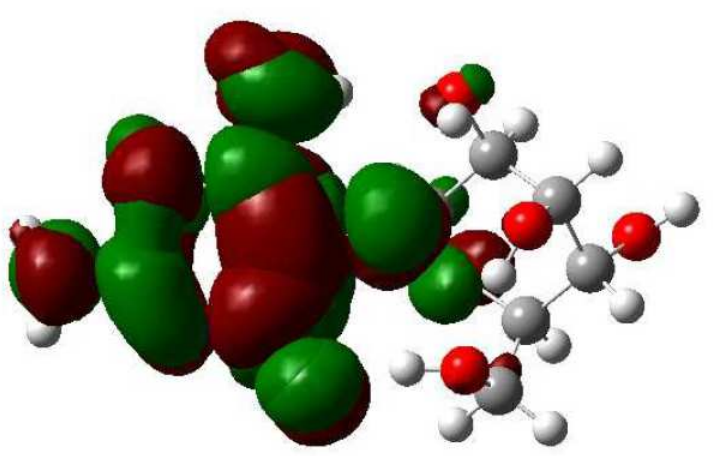

LUMO

Figure 7. Frontier molecular orbital density of vicine: (a) HOMO and (b) LUMO.

On the other hand, the gap between HOMO and LUMO $(\Delta \mathrm{E})$ is an important index to the inhibition efficiency. $\Delta \mathrm{E}$ low values indicate good inhibition efficiency [39].

The optimized equilibrium structure of vicine is shown in Fig. 8. The molecular properties of vicine are listed in Table 5. 


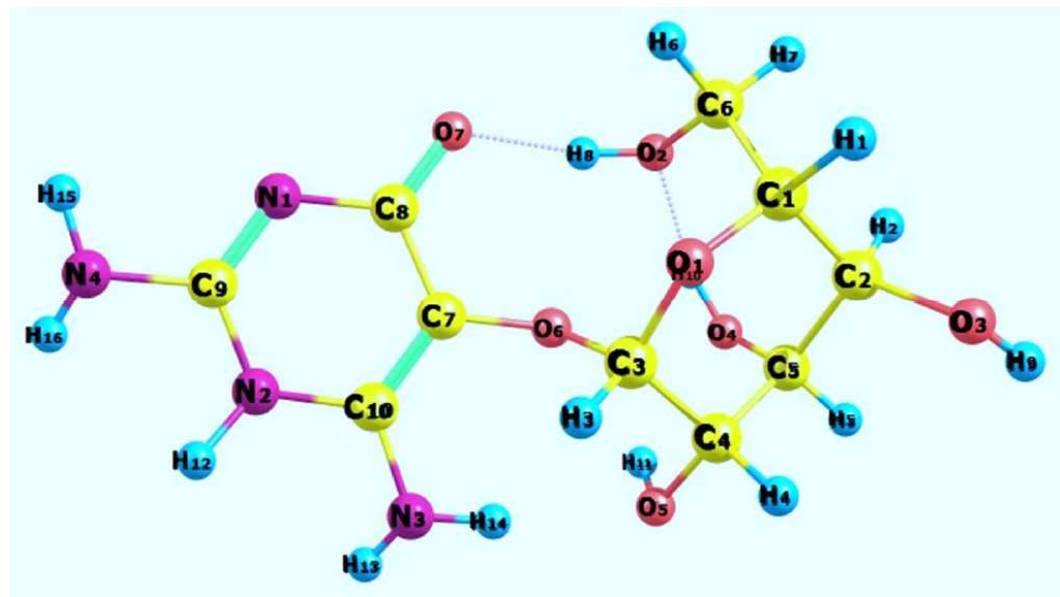

Figure 8. Vicine's optimized structure.

Table 5. Vicine's molecular properties calculated using DFT, at the B3LYP/ 6-31G + G (d.p) basis set.

\begin{tabular}{ccccccccc}
\hline $\mathbf{E}_{\text {номо }}(\mathbf{e V})$ & $\mathbf{E}_{\mathrm{Lumo}}(\mathbf{e V})$ & $\Delta \mathbf{E}(\mathbf{e V})$ & $\boldsymbol{\mu}(\mathbf{D})$ & $\Delta \boldsymbol{N}$ & $\boldsymbol{\eta}$ & $\boldsymbol{\chi}$ & $\boldsymbol{\sigma}$ & $\boldsymbol{\omega}$ \\
\hline-0.295 & -0.141 & 0.154 & 7.6203 & 44.04 & 0.077 & 0.218 & 12.99 & 0.308 \\
\hline
\end{tabular}

Table 5 shows that $\mathrm{E}_{\mathrm{HOMO}}$ high value and $\mathrm{E}_{\mathrm{Lumo}}$ low value, with low $\Delta \mathrm{E}$, supported vicine's inhibition action on the steel's surface.

$\Delta \mathrm{N}$ (Table 5) has a positive value (44.04), where iron electronegativity is $\chi \mathrm{Fe}=$ $7 \mathrm{eV}$, and this value is greater than vicine electronegativity. That means that if the ability of the iron atom to accept electrons increases, then, vicine's adsorption behavior onto the iron surface will also increase. Furthermore, iron's global hardness $\left(\eta_{\mathrm{Fe}}=0\right)$ is lesser than vicine's hardness. Because of the difference between iron and vicine electronegativity, electrons will flow from vicine to iron, until the chemical potentials reach the equilibrium point.

$\Delta \mathrm{N}$ is calculated according to equation 10 [40], when the electron affinity (A) is equal to the ionization potential of the metallic bulk ( $\mathrm{I}=\mathrm{A})$, because iron in the alloy is softer than the neutral iron atoms, as shown in Table 5.

$$
\Delta N=\frac{\chi_{F e}-\chi_{i n h}}{2\left(\eta_{F e}-\eta_{i n h}\right)}
$$

The electronegativity and hardness are calculated according to equations 11 and 12 [41].

$$
\begin{aligned}
& \chi=\frac{I+A}{2} \\
& \eta=\frac{I-A}{2}
\end{aligned}
$$

I and A are calculated from equations 13 and 14.

$$
\begin{aligned}
& \mathrm{I}=-\mathrm{E}_{\text {HOMо }} \\
& \mathrm{A}=-\mathrm{E}_{\text {LUMO }}
\end{aligned}
$$


When $\Delta N$ value is higher than 3.6, the electron donation should be decreased [41]. When we look at vicine's $\Delta N$ value (Table 5), it can be seen that it is 44.04 , which is higher than 3.6. That means that vicine's electron donation is decreased, and that IE was not solely due to vicine's electron donation ability, but also to the electrostatic force of attraction for some protonated sites to the iron surface [41]. Vicine's $\eta$ and $\sigma$, from Table 5, which are equal to 0.077 and 12.99, respectively, indicate that $\eta$ and $\sigma>0$, where $\eta=1 / \sigma$. These results imply that the charge transfer from the iron surface to vicine occurs according to back-donation. That effect is a factor responsible for vicine's inhibitive effect. Similar observation has been reported [41-42].

Furthermore, the global electrophilicity index $(\omega)$ can be calculated according to equation 15:

$$
\omega=\frac{\chi^{2}}{2 \eta}
$$

Table 5 shows that vicine's electrophilicity global index has a small value $(\omega=$ 0.308). That means vicine tends to behave as a nucleophile, and donates electrons to the iron surface [42].



Figure 9. Vicine's Mullikan charges.

Table 6. Vicine's Mullikan charge.

\begin{tabular}{crcccccccc}
\hline Atom & Charge & Atom & Charge & Atom & Charge & Atom & Charge & Atom & Charge \\
\hline $\mathrm{C}_{1}$ & 0.229 & $\mathrm{H}_{5}$ & 0.124 & $\mathrm{C}_{6}$ & -0.171 & $\mathrm{C}_{7}$ & 0.034 & $\mathrm{H}_{12}$ & 0.311 \\
$\mathrm{H}_{1}$ & 0.147 & $\mathrm{C}_{5}$ & -0.022 & $\mathrm{H}_{6}$ & 0.156 & $\mathrm{C}_{10}$ & 0.228 & $\mathrm{~N}_{4}$ & -0.528 \\
$\mathrm{O}_{1}$ & -0.245 & $\mathrm{C}_{3}$ & 0.153 & $\mathrm{H}_{7}$ & 0.127 & $\mathrm{~N}_{3}$ & -0.634 & $\mathrm{H}_{15}$ & 0.328 \\
$\mathrm{C}_{2}$ & -0.061 & $\mathrm{H}_{3}$ & 0.127 & $\mathrm{O}_{2}$ & -0.608 & $\mathrm{H}_{13}$ & 0.298 & $\mathrm{H}_{16}$ & 0.290 \\
$\mathrm{H}_{2}$ & 0.138 & $\mathrm{C}_{4}$ & 0.095 & $\mathrm{H}_{8}$ & 0.447 & $\mathrm{H}_{14}$ & 0.376 & & \\
$\mathrm{O}_{3}$ & -0.529 & $\mathrm{H}_{4}$ & 0.162 & $\mathrm{O}_{6}$ & -0.508 & $\mathrm{~N}_{1}$ & -0.386 & & \\
$\mathrm{H}_{9}$ & 0.350 & $\mathrm{O}_{5}$ & -0.527 & $\mathrm{O}_{7}$ & -0.531 & $\mathrm{C}_{9}$ & 0.365 & & \\
$\mathrm{O}_{4}$ & -0.567 & $\mathrm{H}_{11}$ & 0.390 & $\mathrm{C}_{8}$ & 0.454 & $\mathrm{~N}_{2}$ & -0.451 & &
\end{tabular}

The Mullikan charge values of vicine's atoms, as shown in Fig. 9, are listed in Table 6 . The high negative Mullikan charges density concerned $\mathrm{N}, \mathrm{O}$, and some of the $\mathrm{C}$ atoms. The high negative Mullikan charges density made these atoms ready to adsorb onto the iron surface. In other words, the donating electrons of $\mathrm{N}, \mathrm{O}$, and some of the $\mathrm{C}$ atoms went to the unoccupied orbitals of iron. This means that iron will be attacked by vicine [41]. The positive Mullikan charge on 
vicine will be attacked by the occupied orbitals of iron. Vicine can accept electrons from iron through these atoms. In these cases, vicine's adsorption onto the iron surface will increase, and iron corrosion will decrease.

\section{Conclusions}

Vicine is a very good corrosion inhibitor for carbon steel alloy in a corrosive environment $\left(0.1 \mathrm{M} \mathrm{HCl}\right.$ at $\left.25^{\circ} \mathrm{C}\right)$. Vicine showed high inhibition efficiency (97\%), with optimal concentrations (50 ppm), at $25^{\circ} \mathrm{C}$.

The theoretical calculations of hardness, electronegativity, and an electrophilic index depicted that the inhibitor tends to donate electron density to the alloy, through $\mathrm{O}, \mathrm{N}$, and some of the $\mathrm{C}$ atoms, while the other carbon atoms in the inhibitor receive the electron density from the metal surface in the alloy. $\Delta \mathrm{N}$ and Mullikan charges values gave the same results.

The higher values of inhibition efficiency at 35,45 , and $55^{\circ} \mathrm{C}$ will be $92 \%, 84 \%$ and $74 \%$, respectively.

\section{References}

1. Fouda AS, Abdallah YM, Nabil D. Int J Innov Res Sci, Eng Technol. 2014;3:12965-12982.

2. Al-Sultani1 KF, Abdulsada SA. Int J Adv Res. 2013;1:239-243.

3. Prithiba A, Leelavathi S, Rajalakshmi R. Chem Sci Rev Lett. 2014;3:177187.

4. Buchweishaija J. Tanz J Sci. 2009;35:77-92.

5. Majed RA, Abdullah HA. Int J Eng Sci Res Technol. 2014;3:642-650.

6. Benea L, Danaila E, Dumitraşcu VM. Adv Mater Res. 2016;1139:46-51.

7. Khan G, Newaz KMS, Basirun WJ, et al. Int $J$ Electrochem Sci. 2015;10:6120-6134.

8. Adulkhaleq LG. J Eng Develop. 2013;17:155-169.

9. Patni N, Agarwal S, Shah P. Chin J Eng. 2013;1:1-10.

10. Fouda AS, Badr AH. African J Pure Appl Chem. 2013;7:350-359.

11. Rani BEA, Basu BBJ. Int J Corros. 2012;1:1-15.

12. Bhawsar J, Jain PK, Jain P. Alexandria Eng J. 2015; 54: 769-775.

13. Rocha JC, Gomes JA, D’Elia E. Mater Res. 2014;17:1581-1587.

14. Naema JD. Dhi-Qar J Sci. 2011;2:49-57.

15. Dahmani M, Et-Touhami A, Al-Deyab SS, et al. Int J Electrochem Sci. 2010;5:1060-1069.

16. Ameer MA, Fekry AM. Prog Org Coat. 2011;71:343-349.

17. Fouda AS, Nofal AM, El-Ewady GY, et al. Der Pharma Chem. 2015;7:183197.

18. El-Naggar MM. Corros Sci. 2007;49:2226-2236.

19. Bouklah M, Hammouti B, Larenee M, et al. Corros Sci. 2006;48:2831-2842.

20. Abiola OK, Oforoka NC. J Corros Sci Eng. 2004;7:1-14 .

21. AL-Sawaad HZ. Int J Electrochem Sci. 2013;8:3105-3120. 
22. Fouda AS, Elewady GY, Shalabi K, et al. Int J Innov Res Sci, Eng Technol. 2014;3:11210-11228.

23. Ebenso EE, Eddy NO, Odiongenyi AO. Afr J Pure Appl Chem. 2008;2:107115.

24. Fu JJ, Wang Y, Li SN, et al. J Mater Sci. 2010;45:979-986.

25. Al-Sawaad HZ. Int J Adv Res. 2015;3:343-361.

26. Al-Sahlanee HH, Sultan AA, Al-Faize MM. Aquatic Sci Technol. 2013;1:135-151.

27. Abdallah M, Zaafaranya IA, AL Jahdalya BA. J Mater Environ Sci. 2016;7:1107-1118.

28. Nwosua FO, Muzakir MM. J Mater Environ Sci. 2016;7:1663-1673.

29. Al-Bonayan AM. IJRRAS. 2015;22:49-64.

30. Zaferani SH, Shishesaz MR. J Pet Environ Biotechnol. 2014;5:1-5.

31. Frisch MJ, Trucks GW, Schlegel HB, et al. Gaussian03, Gaussian, Inc., Pittsburgh, PA, 2003.

32. Frisch MJ, et al., GAUSSIAN03, Revision C.02, Gaussian Inc., Wallingford, CT,2004.

33. Becke AD. J Chem Phys. 1993;98:5648.

34. Lee C, Yang W, Parr RG. Phys Rev B. 1988;37:785.

35. Pople JA, Binkley JS, Seeger R. Int J Quant Chem Symp. 1976;10:1.

36. Krishnan R, Kinkley JS, Seeger R, et al. J Chem Phys. 1980;72:650.

37. Obot IB, Ebenso EE, Akpan IA, et al. Int J Electrochem Sci. 2012;7:19781996.

38. Kara YS, Sagding SG, Esme A. Prot Metals Phys Chem Surf. 2012;48:710721.

39. Rajendiran TV, Gunasekaran S. J Chem Biol Phys Sci. 2012;2:1151-1165.

40. Eddy NO, Stoyanov SR, Ebenso EE. Int J Electrochem Sci. 2010;5:11271150.

41. Obot IB, Ebenso EE, Akpan IA, et al. Int J Electrochem Sci. 2012;7:19781996.

42. Kabanda MM, Murulana LC, Ozcan M, et al. Int J Electrochem Sci. 2012;7:5035-5056

43. Ebenso EE, Arselan T, Kandermirli F, et al. Int J Quant Chem. 2010;110:2614-2636. 